\title{
Prospective approach to manage COVID-19-related cytokine storm; an updated review on current concepts
}

\author{
Mohaddeseh Bahmani ${ }^{1}{ }^{\circledR}$, Lillian Saberian ${ }^{2 *}$ \\ ${ }^{1}$ Nickan Research Institute, Isfahan, Iran \\ ${ }^{2}$ Independent Researcher and Author, Toronto, Ontario, Canada
}

Correspondence to:

Lillian Saberian, Email:

leilasbrn626@gmail.com

Received: 3 May 2021

Accepted: 7 Aug. 2021

ePublished: 21 Aug. 2021

Keywords: SARS-CoV-2, COVID-19, Inflammation, Pathogenesis, Cytokine storm Cytokine release syndrome

Citation: Bahmani M, Saberian L. Prospective approach to manage COVID-19-related cytokine storm; an updated review on current concepts. J Prev Epidemiol. 2021;6(1):e20. doi: $10.34172 /$ jpe.2021.20

\begin{abstract}
Coronavirus disease 2019 or COVID-19, caused by the novel human coronavirus named severe acute respiratory syndrome coronavirus 2 (SARS-CoV-2), first emerged in late 2019, in the city of Wuhan, Hubei province, China. Unfortunately, despite many efforts to find cures for SARS-CoV-2 disease, still the management of severe cases remains challenging. In severe forms of COVID-19, proinflammatory cytokines are notably elevated (3) and reminiscent of the secondary hemophagocytic lymphohistiocytosis (HLH). According to many studies, immune imbalance and an uncontrolled massive release of inflammatory cytokines have a significant role in COVID-19 severity and ARDS pathophysiology. Accordingly, targeting the over-activated immune system to prevent tissue damage is now one of the most noticed possible strategies to manage severe COVID-19 cases. In the present study, we reviewed studies and clinical trials conducted in this regard.
\end{abstract}

\section{Introduction}

Coronavirus disease 2019 or COVID-19, caused by the novel human coronavirus named severe acute respiratory syndrome coronavirus 2 (SARS-CoV-2), first emerged in late 2019, in the city of Wuhan, Hubei province, China. The virus was rapidly transmitted from human to human with a global spread, and it was further declared as a pandemic by the World Health Organization (WHO) on March 11, 2020 (1). Up to December 18, 2020, there were 72851747 confirmed cases and 1643339 related deaths (2).

Coronaviruses have been existed for a long time and have often been identified as the causes of mild gastrointestinal or respiratory illnesses. However, coronaviruses with high pathogenicity causing severe diseases have emerged over the past two decades; severe acute respiratory syndrome coronavirus 1 (SARS-CoV-1), which appeared in Guangdong province of China in 2002, and Middle East respiratory syndrome coronavirus (MERS-CoV), which caused a breakout in the Middle East in 2013. Both these diseases and COVID-19 had animal origins (zoonotic diseases) (1). Most of the time, COVID-19 appears initially with fatigue, fever, loss of appetite, cough,

\begin{abstract}
Key point
Targeting the over-activated immune system to prevent tissue damage is now one of the most noticed possible strategies to manage severe COVID-19 cases.
\end{abstract}

diarrhea, and myalgia. Various complaints like shortness of breath and subsequent acute respiratory distress syndrome (ARDS) were detected in severe cases. In these cases, kidney, liver, and heart damage can also eventually induce shock and death (3). This virus transmitted via respiratory aerosols of an infected individual, after inhalation by other persons, infects them (4).

Coronaviruses belong to the Coronaviridae family, Nidovirales order. They are the enveloped viruses with a positive-sense single-stranded RNA genome. They are also intersected into four genera: alpha, beta, gamma, and delta, according to the electron microscopic findings. The novel coronavirus belongs to the beta-coronaviruses genus. These viruses have projections on their envelope surfaces called "spike glycoprotein," or $S$ protein (5). The virus enters the cells by the interplay between ACE- 2 on the host cellular surface and viral spike protein (6). This receptor presenting on the surfaces of

Copyright (C) 2021 The Author(s); Published by Society of Diabetic Nephropathy Prevention. This is an open-access article distributed under the terms of the Creative Commons Attribution License (http://creativecommons.org/licenses/by/4.0), which permits unrestricted use, distribution, and reproduction in any medium, provided the original work is properly cited. 
different human cells such as proximal tubular kidney cells, lung epithelial cells, cardiovascular tissue cells, and gastrointestinal tract, causes the infection of these cells by the virus and subsequent related manifestations (7). Unfortunately, despite many efforts to find cures for SARSCoV-2 disease. Therefore, the management of severe cases remains challenging (8). In October 2020, the US Food and Drug Administration (FDA) approved remdesivir to treat hospitalized patients with SARS-CoV-2 of 12 years of age and older and a weight of at least $40 \mathrm{~kg}$. Its rationale was several phase 3 clinical trials on hospitalized individuals with various disease severities (9). It is the only drug with FDA approval for this virus. Other remedies only have received Emergency Use Authorization (EUA) (10).

"Cytokine storm," first used to describe graft-versushost disease in 1993, is an overreaction of the host immune system to an infectious agent that causes severe tissue damage and death. While the inflammatory cytokines help fight the pathogen, the exact line between the appropriate immune response and the over-harmful response is unclear, and a sole definition for this term has not yet been admitted. In general, immune system disorders, leading to multi-organ failures, called the cytokine storm. This cytokine storm creates fatigue, fever, neurological symptoms, myalgia, diarrhea, anorexia, and rash. It may also lead to disseminated intravascular coagulation, cholestasis, kidney damage, cardiovascular injury, and ARDS (11). Manifestations of this syndrome are mainly due to the inflammatory cytokines such as TNF- $\alpha$, IFN- $\gamma$, IL-1, IL-6, and IL-18, while both inflammatory and antiinflammatory mediators elevate in the cytokine storm. Cytokine storm was previously reported in SARS-CoV and MERS-CoV (12,13), influenza H1N1 (14), and influenza H5N1(15) (16)

In severe forms of COVID-19, pro-inflammatory cytokines are notably elevated (3) and reminiscent of the secondary hemophagocytic lymphohistiocytosis (HLH) (17). It is assumed to be involved in the development of several serious and potentially fatal disease complications such as thromboembolic events, ARDS, vasculitis, encephalitis, acute renal and liver damages, and neurological involvement and also may be a key in the development of a more severe illness in the elderly and individuals with comorbidities $(7,18)$. According to many studies, immune imbalance and an uncontrolled massive release of inflammatory cytokines have a significant role in COVID-19 severity and ARDS pathophysiology (19). Accordingly, targeting the over-activated immune system to prevent tissue damage is now one of the most noticed possible strategies to manage severe COVID-19 cases.

In the present study, we reviewed studies and clinical trials conducted in this regard.

\section{Methods}

Data were collected in Scopus, EBSCO, Google Scholar, Web of Science, and PubMed databases. The keywords used SARS-CoV-2, COVID-19, inflammation, pathogenesis, immunotherapy, anti-inflammatory, immunomodulation, coronavirus, cytokine storm, and cytokine release syndrome. In addition to search terms, we limit data collection to research and review articles written in English only.

Current knowledge about SARS-CoV-2 pathogenesis This virus binds to ACE2 on the target cell by its S protein and after that, $S$ protein cleavage by a protease like cathepsin facilitates virus and membrane fusion and virus entry to the target cell (8). Following the extensive cellular damage after becoming infected with the virus, dead cell debris can elicit a macrophage-dependent inflammatory response (20). Endothelial cells are also contributed to the pulmonary damage process as they facilitate the cumulating and extravasation of neutrophils and leukocytes (21). Accordingly, macrophages of the alveolar tissue express ACE2 and can become directly infected by the virus $(20,22)$ (Figure 1). In severe forms of the disease, several abnormalities in the immune system function, including lymphopenia, neutrophilia, lymphocyte dysfunction, increased pro-inflammatory cytokines, monocyte, and granulocyte dysfunction, are seen. The proportion of neutrophils to lymphocytes is an essential predicting factor for disease severity. T-cells show elevated levels of T cell immunoglobulin domain and mucin domain-3 (TIM3), killer cell lectin-like receptor subfamily $\mathrm{C}$ member 1 (NKG2A), and programmed cell death protein-1 (PD1) on their surface (23). Interleukin-6 (IL6), tumor necrosis factor-alpha (TNF- $\alpha)$, interferon-gamma (IFN- $\gamma$ ), and interleukin-1 gamma (IL- $1 \gamma$ ) are released during the cytokine release phase (24), and severe cases are associated with a significant release of inflammatory mediators such as CRP, interleukin-6, and ferritin (25). Interstitial edema observed in SARS-CoV--2 victims' lung biopsies is mainly caused by incremented capillary permeability due to the effects of TNF (24). Besides, IP10, MCP1, IL-1RA, IL$1 \beta$, IL-2R, IL-6-10, IFN- $\gamma$, TNF- $\alpha$, GM-CSF, and G-CSF levels are heightened in both severe and non-severe SARSCoV-2 infected individuals. However, it is more drastic in severe cases. GM-CSF produced by Th1 cells progresses the inflammatory process by inducing CD14+CD16+ monocytes and release of IL-6 (23).

Th-17 plays several pro-inflammatory roles by producing GM-CSF, IL-17, IL-21, and IL-22. However, the immune system must fight against pathogens. TNF- $\alpha$ and IL- $1 \beta$ raise its function. The presence of the Th-17 linked cytokine storm has been observed in COVID-19, H1N1 influenza, MERS-CoV, and SARS-CoV (26).

In one post-mortem investigation, two victims' lung biopsies showed filling of the alveoli with lymphocytes, neutrophils, macrophages, and diffuse alveolar damage. Alveolar macrophages in these patients had expressed significant levels of programmed death-ligand 1, IL-10, IL-6, and TNF- $\alpha$. Alveolar macrophages are key immune 


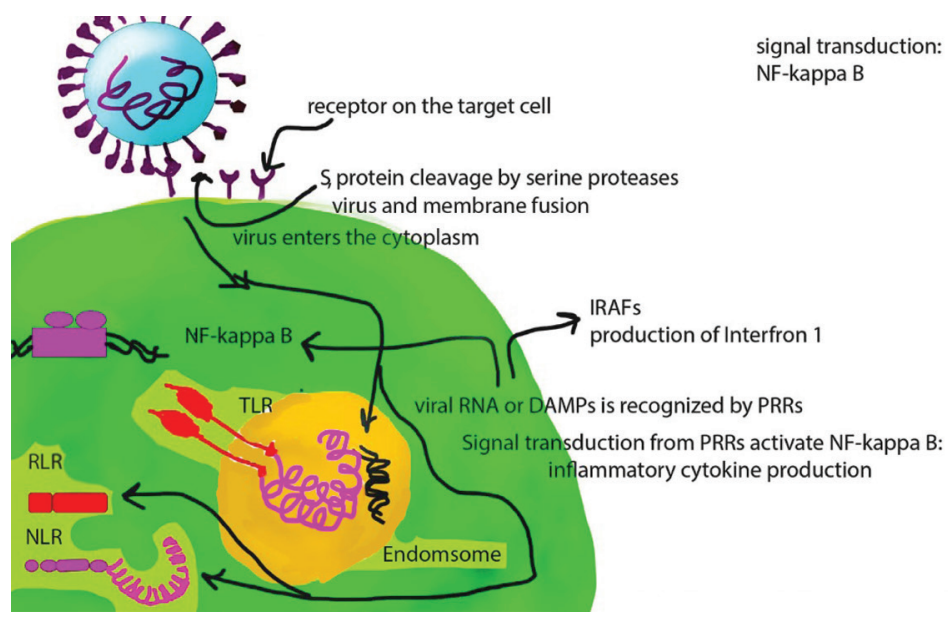

Figure 1. After a pathogen enters the human's body, it is recognized by RPRs in the innate immune system, and when target cells get infected with the pathogen, damage-associated molecular patterns (DAMPs) are recognized by them. The production of inflammatory cytokines enhances through signaling from these receptors. The genes of these cytokines are expressed following the activation of the NF kappa B pathway. Following activation of the IRF pathway, after TLRs or RLRs recognize the viral RNA, the antiviral response is induced by interferons' expression. Additionally, macrophages can get directly infected by SARS-CoV-2 as they express ACE 2; NF-kappa B. S protein (spike protein), TLR (toll like receptor),NLR, NOD like receptor, RLR,PRR and IRAF.

cells in the development of cytokine release syndrome in the course of SARS-CoV-2 (6). Although inflammatory mediators are increased in SARS-CoV-2 patients, the IFN$1(\alpha, \beta)$ related response is attenuated and delayed (27), which is vital in the host defense against viruses. However, some other studies have shown that IFNs are increased in severe forms of the disease and may be associated with disease severity (28).

Hyper-inflammation and immune response failure (immunoparalysis) are present in this disease; the proportion of these two differs in different individuals and different disease stages. Although IL-10 is an antiinflammatory mediator, it was significantly related to the disease intensity and acute renal failure development in COVID-19 patients in a previous study, even more than pro-inflammatory mediators such as IL-6. This virus can infect lymphocytes and then, IL-10 production results in cell apoptosis and causes lymphopenia (29). According to the immune response against the virus, there are three phases in SARS-CoV-2 disease. In the first phase, PAMPs (pathogen-associated molecular pattern) activates the innate immune system. In the second phase, the adaptive immune system acts, and the patient becomes symptomatic. In the third phase or the cytokine release phase, severe symptoms appear due to the excessive release of inflammatory mediators (30). In general, an imbalanced immune response leads to cytokine storm development and organ failure (21,30-33) (Figure 2).

Potential therapeutic options to manage SARS-CoV-2 related cytokine storm

Corticosteroids

In previous studies, early administration of corticosteroids in MP infections and influenza has been influential in the recovery of pulmonary lesions (33). In a meta-analysis of seven clinical trials (including 1703 seriously ill SARS-
CoV-2 patients), three trials were on dexamethasone, one on methylprednisolone, and three on hydrocortisone. In this study, corticosteroid therapy was associated with a decreased all-cause mortality rate 28 days after randomization with no serious safety concerns. However, severe adverse effects were reported in six trials $(18.1 \%$ of the individuals randomized to the corticosteroids treated group) (34). In a retrospective study in Wuhan during the first months of the disease on 102 seriously ill SARS-CoV-2 patients, 69 patients received methylprednisolone, and others did not receive it. Regarding disease prognosis and clinical improvement, no significant difference was found comparing these two groups (35). In adult patients with SARS-CoV-2 and ARDS, systemic use of corticosteroids is suggested because it is shown to reduce mortality in these cases (17).

Corticosteroids have been previously used to treat SARS-CoV and MERS-CoV pulmonary diseases, but they did not show enough efficacy and even were damaging (36). A meta-analysis of 15 cohort studies on the effects of corticosteroids in patients with influenza showed that these drugs were associated with heightened mortality rates (17). Recently, a preliminary report of a multi-center randomized open-labeled clinical trial (RECOVERY) indicated the positive effects of dexamethasone in clinical improvement of severely ill SARS-CoV-2 patients who needed supportive respiratory care but not in patients who did not need supplementary oxygen (37).

\section{Anti-IL-6}

As IL-6 plays a crucial role in the cytokine storm, agents that reduce IL-6 signal transduction may barricade from fatal SARS-CoV-2 complications (38). To this rationale, attention has been recently paid toward IL-6 blockade to manage COVID-19 severe cases. Tocilizumab, siltuximab, and sarilumab are medications with anti-IL-6 activities 


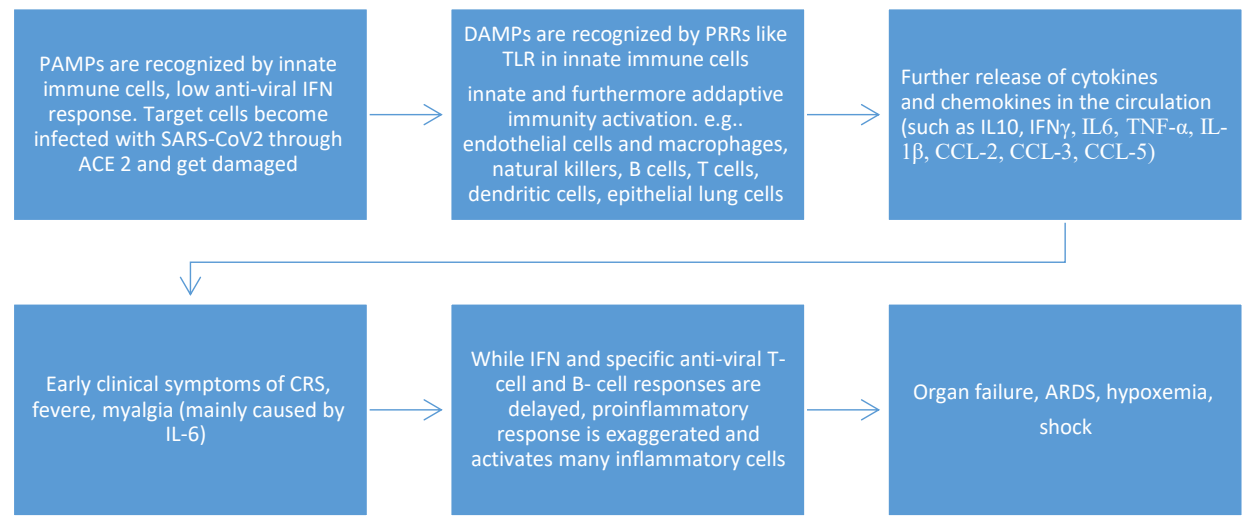

Figure 2. Cytokine storm development in the course of COVID-19.

(39). Tocilizumab was first constructed in the 1990s and is one of the first drugs used to suppress the immune system. It is a monoclonal antibody against the human IL-6 receptor (11). Many studies have assessed the effectiveness of this drug in the treatment of COVID-19 and found different results. According to the results of a metaanalysis study, tocilizumab could reduce the mortality rate in severe COVID-19 patients (40). Results of clinical trials are also repugnant $(25,41,42)$.

\section{Anti-TNF}

According to a meta-analysis, these agents improve patients' survival in sepsis (43). TNF causes pulmonary capillary leakage in patients with COVID-19 (44). Biological agents that antagonize the inflammatory cascade of TNF may have beneficial effects in the treatment of SARS-CoV-2. Accordingly, inflammatory bowel disease patients under anti-TNF therapy had lower mortality rates than those under sulfasalazine, mesalamine, or steroid therapies. The risk of super-infection may increase with the use of these antibodies (45). Additionally, these medications have been entered in randomized clinical trials (\#NCT04425538).

\section{Interferon}

Although IFN 1 is essential in the defense against viruses, it also has pro-inflammatory activities, shown in mouse models of SARS (46).

Nebulized interferon alfa- $2 b$ in addition to umifenovir decreased systemic inflammation compared with umifenovir alone in a retrospective cohort study. In this study, there were 77 participants, and patients in the treatment group were significantly younger than those in the control group (47). Interferon $\alpha$ and $\beta$ are currently under investigation in clinical trials.

Janus kinase (JAK)/signal transducers and activators of transcription (STAT) inhibitors

Although JAK/STAT signaling is crucial in viral eliminating and IFN response, it plays a significant role in activating the immune cells and developing the cytokine storm. Viruses like the novel coronavirus can escape from the immune system by inhibiting this pathway. JAK/STAT signaling is activated after inflammatory mediators such as IL-6 or IFN bind to their target cells' receptors. Ruxolitinib, a JAK 1 and 2 inhibitor, is currently being evaluated under a phase 3 clinical trial for its efficacy in reducing SARS-CoV-2 serious complications in hospitalized individuals (48). Fedratinib, a JAK2 inhibitor, reduces IL-17 production by Th-17 cells and eventually prevents Th-17 related cytokine storm in mice models (26). JAK inhibitors can inhibit the phosphorylation of proteins being necessary for signal transduction by cytokines (49).

\section{Anti-IL-23 and 17}

Recent studies showed that IL-23 and IL-17 blockade had been accompanied by positive effects in COVID-19 in psoriasis patients (50). Ixekizumab is an IL-17A binding monoclonal antibody. This drug's effect after adding to the antiviral therapy is currently under investigation in a clinical trial (50). There is not further clinical data available on the effect of these drugs in COVID-19.

\section{Antimalarial medications}

Hydroxychloroquine is an antimalarial drug with antiinflammatory effects used in the treatment of SLE and RA. This drug was previously recommended in SARS-CoV-2. However, scientists advised that its use should be with caution due to the possible adverse effects (51). Currently, chloroquine or hydroxychloroquine are not recommended in either non-hospitalized or hospitalized individuals with SARS-CoV-2 for treatment (52).

Another antimalarial drug is artesunate. A study in 2016 to evaluate the possible effects of artemisinin in managing burn-related sepsis in BALB/c mice found that neutrophil infiltration in the heart and lungs and inflammatory cytokines production was reduced in treated mice after randomization by preventing the NLRP3 inflammasome in macrophages. It lowered IL-18 and IL-1 $\beta$ levels in treated mice (53). In severe malaria cases, the production of inflammatory cytokines, 
mainly TNF and IL-6, is heightened and correlates with the disease severity. After treatment with artesunate, the concentration of these inflammatory mediators reduced. (54)_Immunomodulatory actions of artesunate are mainly through inhibiting NFKB (55). Moreover, in vitro artemisinin-based combination therapy activity against SARS-CoV-2 replication is shown in a study (56). Artesunate has recently entered COVID-19 clinical trials too.

\section{Anti-IL-1}

In a recent prospective cohort study, 78 seriously ill SARSCoV-2 patients were evaluated for their clinical response to anakinra, an IL-1 receptor antagonist. In this study, the decrease in plasma concentrations of procalcitonin, ferritin, and white blood cell counts showed that this treatment effectively reduced the clinical inflammatory indicators (57). Another cohort study also reported that anakinra decreased death risk in the treatment group relative to the control group (58).

\section{Retinoic acid}

One recent study showed that retinoic acid was efficient in ameliorating human bronchial epithelial cell culture model (16HBE) function and attenuating the barrier leakage induced by inflammatory cytokines. This agent also affected the tight junctional complex and somewhat inversed TNF- $\alpha$ 's effects on these proteins (59).

\section{Mesenchymal stem cells}

A case report of successful SARS-CoV-2 treatment with human umbilical cord mesenchymal stem cells (hUCMSC) in a critically ill 65-year-old female patient with multi-organ failure showed that it was influential in clinical improvement. This patient had typical signs of COVID-19, a past medical history of diabetes and hypertension, and a positive RT-PCR test for this virus. A non-invasive mechanical ventilator was used, and the patient received Xuebijing, methylprednisolone, moxifloxacin, lopinavir/ ritonavir, IFN-inhalation, and immunoglobulin for treatment. The patient developed multi-organ damage and ARDS despite the appropriate treatment, and she was transferred to the ICU. The patient also had elevated CRP, procalcitonin, and $\mathrm{D}$-dimer levels in addition to relative lymphopenia and neutrophilia. After administration of the allogeneic hUCMSCs in addition to thymosin al, the patient's clinical status improved, laboratory markers of organ injury went down, the lymphocyte count also was increased, and it was not associated with any serious adverse side effects. While thymosin $\alpha 1$ had been started for the patient before administering hUCMSCs, clinical improvement was probably the result of hUCMSCs administration (60).

Furthermore, in a randomized clinical trial on 41 SARS-CoV-2 patients, 12 patients who received hUCMSC showed less mortality and clinical deterioration than the control group; however, this difference was not significant. In the treatment group, inflammatory mediators like IL-6 went down faster, and diabetic patients in this group had a lessened need for insulin. The efficacy, safety, and exact mechanism through which hUCMSC could help treat the severe SARS-CoV-2 cases need further investigation. However, there is evidence showing its immunomodulatory effects and ability for tissue repair (61).

\section{Intravenous immunoglobulin}

Intravenous immunoglobulin (IVIG) has immunomodulatory effects with unknown mechanisms. In treating COVID-19 encephalopathy, it has been effective and safe in clinical improvement and decreasing inflammatory mediators (62). It is used in the treatment of viral and bacterial sepsis. A cohort study showed that IVIG could significantly decrease mortality and the inflammatory response and ameliorated organ failure in patients with critical status. In this study, an initial high-dose administration of IVIG (>15 g/d) was effective in seriously ill patients and improved prognosis (63).

\section{Antibiotics}

Doxycycline has anti-inflammatory effects and has been effective in SARS-CoV-2 patients' clinical improvement in recent clinical trials. However, due to the risk of microbial resistance, its use should be with caution and restricted, and it is not recommended in mild to moderate cases (64).

\section{Metformin}

Metformin is a biguanide used to treat diabetes mellitus that has mitochondrial effects. Mitochondria has a role in programmed cell death related to the release of apoptotic signaling molecules (65). Metformin can inhibit NF- $\kappa B$ signaling and mitochondrial enzymes and, therefore, gene expression of inflammatory cytokines like IL-6 (66). A meta-analysis of five studies with 6937 patients showed that metformin decreases COVID-19 related mortality rates (67).

\section{Convalescent plasma}

The convalescent plasma from recovered individuals with sufficient antibody titers has been attracted attention as a therapeutic option (68). There are many ongoing clinical trials in this regard; for example, RESCUE is an ongoing clinical trial to evaluate convalescent plasma's efficacy and safety in treating old-aged adults with SARS-CoV-2.

\section{Other agents with possible anti-inflammatory effects} Icosapent ethyl is a remedy to control hypertriglyceridemia if the maximum dosage of statins is insufficient. This drug has anti-inflammatory functions, and a recently published study revealed its efficacy in the clinical improvement of three COVID-19 patients admitted in ICU(69).

Several pharmaceutical active natural products (PANPs) have shown anti-inflammatory effects and lung protection against ARDS in animal models. For example, in previous 
studies, omentin and vaspin mitigated inflammatory response in mice with ARDS induced by lipopolysaccharide (LPS), berberine inhibited NF- $\kappa$ B pathway activation, and tetrahydroberberine was associated with a decrease in inflammatory mediators' levels like TNFa (21).

Emodin is a plant-extracted flavonoid. In mouse models of asthma, it has shown anti-inflammatory effects by preventing STAT6 (signal transduction and activation of transcription) phosphorylation and activated macrophage polarization. Another flavonoid, scutellarein, inhibits the NF- $\kappa B$ pathway and subsequently suppresses the expression of inducible nitric oxide synthase and cyclooxygenase-2 (8).

A study on severe SARS-CoV-2 patients' peripheral blood mononuclear cells indicated that GSK-LSD-1, an inhibitor of lysine-specific demethylase 1 (LSD1) phosphorylation, reduced cytokine production in vitro. Phosphorylated LSD1 stabilizes NF- $\kappa \mathrm{B}$ p 65 to regulate the gene expression of pro-inflammatory cytokines (70).

Peroxisome proliferator-activated receptor gamma $($ PPAR- $\gamma)$ is a nuclear receptor that has a role in inflammation through regulating related gene expression and is vastly expressed in the adipose tissue. Gammaoryzanol has shown a reduction in adipose tissue inflammatory status in male Wistar rats treated with this agent in a previous study (71).

Pentoxifylline, a xanthine derived drug, down-regulates the pro-inflammatory adenosine receptor A2A pathway (A2AR) and lowers expression rates of IL1b, IL6, TNF $\alpha$, ICAM1, IFN $\gamma$, VCAM1, and the production of inosine and adenosine. This drug diminishes cytokine release from the lung macrophages isolated from individuals with sarcoidosis. In rats, it ameliorates pulmonary function and glomerular injury, while in sepsis, down-regulates several inflammatory cytokines. Pentoxifylline does not have any direct antiviral effect (24).

\section{Ongoing clinical trials}

Since the pandemic onset in December 2019, many clinical trials have been registered to evaluate the possible immunomodulation effects in COVID-19 prognosis. We provided a list of ongoing clinical trials concerning the main immunomodulatory treatments and their possible side effects in online Table S1.

\section{Conclusion}

COVID-19 is currently a pandemic that has affected most countries around the world and millions of people. The possibility of its fatality in severe cases and the lack of any definitive vaccines or treatments necessitates the need for ongoing studies to find a cure. Targeting the cytokine storm with immunomodulatory medications is one of the potential treatment options, encouraging preliminary reports in some aspects. Performing further studies to evaluate the efficacy and safety of these remedies in the future is needed.
Authors' contribution

Primary draft by MB. Edit of the manuscript by LS. All authors read and signed the final paper.

Conflict of interests

The authors declare no conflict of interest.

Ethical considerations

Ethical issues (including plagiarism, data fabrication, double publication) have been completely observed by the authors. Written consent was obtained from the patient for publication of the study.

Funding/Support

None.

Supplementary Materials

Supplementary file 1 contains Table S1.

References

1. Rastogi M, Pandey N, Shukla A, Singh SK. SARS coronavirus 2: from genome to infectome. Respir Res. 2020;21:1-15 doi: 10.1186/s12931-020-01581-z.

2. WHO Coronavirus Disease (COVID-19) Dashboard [Internet] [cited 2020 Dec 18]. Available from: https://covid19.who.int/ table.

3. Berlin DA, Gulick RM, Martinez FJ. Severe Covid-19. N Engl J Med. 2020;383:2451-2460. doi: 10.1056/NEJMcp2009575.

4. Chowdhury MA, Hossain N, Kashem MA, Shahid MA, Alam A. Immune response in COVID-19: A review. J Infect Public Health. 2020;13:1619-1629 doi: 10.1016/j.jiph.2020.07.001.

5. Ye Q, Wang B, Mao J. The pathogenesis and treatment of the 'Cytokine Storm' in COVID-19.' J Infect. 2020;80:607-613 doi: 10.1016/j.jinf.2020.03.037.

6. Wang C, Xie J, Zhao L, Fei X, Zhang H, Tan Y, et al. Alveolar macrophage dysfunction and cytokine storm in the pathogenesis of two severe COVID-19 patients. EBioMedicine. 2020;57:102833 doi: 10.1016/j.ebiom.2020.102833.

7. Bhaskar S, Sinha A, Banach M, Mittoo S, Weissert R, Kass JS, et al. Cytokine Storm in COVID-19-Immunopathological Mechanisms, Clinical Considerations, and Therapeutic Approaches: The REPROGRAM Consortium Position Paper. Front Immunol. 2020;11:1648 doi: 10.3389/ fimmu.2020.01648.

8. Xian Y, Zhang J, Bian Z, Zhou H, Zhang Z, Lin Z, et al. Bioactive natural compounds against human coronaviruses: a review and perspective. Acta Pharm Sin B. 2020;10:1163-1174. doi: 10.1016/j.apsb.2020.06.002.

9. Rubin D, Chan-Tack K, Farley J, Sherwat A. FDA Approval of Remdesivir - A Step in the Right Direction. N Engl J Med. 2020;383:2598-2600. doi: 10.1056/NEJMp2032369.

10. Emergency Use Authorization | FDA [Internet]. [cited 2021 Jan 10]. Available from: https://www.fda.gov/emergencypreparedness-and-response/mcm-legal-regulatory-and-policyframework/emergency-use-authorization\#coviddrugs.

11. Fajgenbaum DC, June $\mathrm{CH}$. Cytokine Storm. Longo DL, editor. N Engl J Med. 2020;383:2255-2273. doi: 10.1056/ NEJMra2026131.

12. Lau SKP, Lau CCY, Chan K-H, Li CPY, Chen H, Jin D-Y, et al. Delayed induction of proinflammatory cytokines and suppression of innate antiviral response by the novel Middle East respiratory syndrome coronavirus: implications for pathogenesis and treatment. J Gen Virol. 2013;94:2679-2690. doi: 10.1099/vir.0.055533-.

13. Channappanavar R, Perlman S. Pathogenic human coronavirus infections: causes and consequences of cytokine storm and immunopathology. In: Seminars in immunopathology. 
Springer; 2017. p. 529-539. doi: 10.1007/s00281-017-0629-x.

14. Woo PCY, Tung ETK, Chan K-H, Lau CCY, Lau SKP, Yuen K-Y. Cytokine profiles induced by the novel swine-origin influenza $\mathrm{A} / \mathrm{H} 1 \mathrm{~N} 1$ virus: implications for treatment strategies. J Infect Dis. 2010;201:346-353 doi: 10.1086/649785.

15. Ishikawa T. Clinical preparedness for cytokine storm induced by the highly pathogenic H5N1 influenza virus. J. Pharmacogenomics Pharmacoproteomics. 2012;3:e131 doi: 10.4172/2153-0645.1000e131.

16. Kalaiyarasu S, Kumar M, Senthil Kumar D, Bhatia S, Dash SK, Bhat $\mathrm{S}$, et al. Highly pathogenic avian influenza $\mathrm{H} 5 \mathrm{~N} 1$ virus induces cytokine dysregulation with suppressed maturation of chicken monocyte-derived dendritic cells. Microbiol Immunol. 2016;60:687-693. doi: 10.1111/1348-0421.12443.

17. Alhazzani W, Møller MH, Arabi YM, Loeb M, Gong MN, Fan E, et al. Surviving Sepsis Campaign: Guidelines on the Management of Critically III Adults with Coronavirus Disease 2019 (COVID-19). Crit Care Med. 2020;48:e440-e469. doi: 10.1097/CCM.0000000000004363.

18. Mubarak M, Nasri H. COVID-19 nephropathy; an emerging condition caused by novel coronavirus infection. J Nephropathol. 2020;9:e21 doi: 10.34172/jnp.2020.21.

19. Potere N, Di Nisio M, Cibelli D, Scurti R, Frattari A, Porreca E, et al. Interleukin-6 receptor blockade with subcutaneous tocilizumab in severe COVID-19 pneumonia and hyperinflammation: A case-control study. Ann Rheum Dis. 2021;80:1-2. doi: 10.1136/annrheumdis-2020-218243.

20. Panigrahy D, Gilligan MM, Huang S, Gartung A, Cortés-Puch I, Sime PJ, et al. Inflammation resolution: a dual-pronged approach to averting cytokine storms in COVID-19? Cancer Metastasis Rev. 2020;39:337-340. doi: 10.1007/s10555-02009889-4.

21. Amaral-Machado L, Oliveira WN, Rodrigues VM, Albuquerque NA, Alencar ÉN, Egito EST. Could natural products modulate early inflammatory responses, preventing acute respiratory distress syndrome in COVID-19-confirmed patients? Biomed Pharmacother. 2020;134:111143. doi: 10.1016/j. biopha.2020.111143.

22. Abul K. Abbas, Andrew H. Lichtman SP, Lichtman AH, Pillai S. Innate immunity. In: Basic Immunology: Functions and Disorders. 5th ed. Philadelphia: Elsevier; 2016. p 30-34.

23. Yang L, Liu S, Liu J, Zhang Z, Wan X, Huang B, et al. COVID-19: immunopathogenesis and Immunotherapeutics. Signal Transduct Target Ther. 2020;5:128. doi: 10.1038/s41392-02000243-2.

24. Hendry BM, Stafford N, Arnold AD, Sangwaiya A, Manglam $\mathrm{V}$, Rosen SD, et al. Hypothesis: Pentoxifylline is a potential cytokine modulator therapeutic in COVID-19 patients. Pharmacol Res Perspect. 2020;8:e00631. doi: 10.1002/ prp2.631.

25. Stone JH, Frigault MJ, Serling-Boyd NJ, Fernandes AD, Harvey L, Foulkes AS, et al. Efficacy of Tocilizumab in Patients Hospitalized with Covid-19. N Engl J Med. 2020;383:23332344. doi: 10.1056/NEJMoa2028836.

26. Wu D, Yang XO. TH17 responses in cytokine storm of COVID-19: An emerging target of JAK2 inhibitor Fedratinib. J Microbiol Immunol Infect. 2020;53:368-370. doi: 10.1016/j. jmii.2020.03.005.

27. Hadjadj J, Yatim N, Barnabei L, Corneau A, Boussier J, Smith $\mathrm{N}$, et al. Impaired type I interferon activity and inflammatory responses in severe COVID-19 patients. Science. 2020;369:718-724. doi: 10.1126/science.abc6027.

28. Lee JS, Park S, Jeong HW, Ahn JY, Choi SJ, Lee H, et al. Immunophenotyping of covid-19 and influenza highlights the role of type i interferons in development of severe covid- 19 . Sci Immunol. 2020;5:49. doi: 10.1126/sciimmunol.abd1554.
29. Henry BM, Benoit SW, Vikse J, Berger BA, Pulvino C, Hoehn $\mathrm{J}$, et al. The anti-inflammatory cytokine response characterized by elevated interleukin-10 is a stronger predictor of severe disease and poor outcomes than the pro-inflammatory cytokine response in coronavirus disease 2019 (COVID-19). 2020;59(3):599-607. doi: 10.1515/cclm-2020-1284.

30. Calabrese LH, Lenfant $\mathrm{T}$, Calabrese C. Interferon therapy for COVID-19 and emerging infections: Prospects and concerns. Cleve Clin J Med. 2020. doi: 10.3949/ccjm.87a.ccc066.

31. Shimabukuro-Vornhagen $A$, Gödel P, Subklewe M, Stemmler HJ, Schlößer HA, Schlaak M, et al. Cytokine release syndrome. J Immunother Cancer. 2018;6:56 doi: 10.1186/s40425-0180343-9.

32. Fara A, Mitrev Z, Rosalia RA, Assas BM. Cytokine storm and COVID-19: a chronicle of pro-inflammatory cytokines: Cytokine storm: The elements of rage! Open Biol. 2020;10:200160. doi: 10.1098/rsob.200160.

33. Lee KY, Rhim JW, Kang JH. Immunopathogenesis of COVID-19 and early immunomodulators. Korean J Pediatr. 2020;63:239_ 50 .

34. Murthy S, Diaz J V, Slutsky AS, Villar J, Angus DC, Annane $D$, et al. Association between administration of systemic corticosteroids and mortality among critically III patients with COVID-19. JAMA. 2020;324:1330. doi: 10.1001/ jama.2020.17023.

35. Zhu H-M, Li Y, Li B-Y, Yang S, Peng D, Yang X, et al. Effect of methylprednisolone in severe and critical COVID-19: Analysis of 102 cases. World J Clin Cases. 2020;8:5952. doi: 10.12998/ wjcc.v8.i23.5952.

36. Korsukewitz C, Reddel SW, Bar-Or A, Wiendl H. Neurological immunotherapy in the era of COVID-19-looking for consensus in the literature. Nat Rev Neurol. 2020;16:493-505. doi: 10.1038/s41582-020-0385-8.

37. Dexamethasone in Hospitalized Patients with Covid-19 — Preliminary Report. N Engl J Med. 2020. doi: 10.1056/ NEJMoa2021436.

38. Tanaka T, Narazaki $M$, Kishimoto T. Immunotherapeutic implications of IL-6 blockade for cytokine storm. Immunotherapy. 2016;8:959-970. doi: 10.2217/imt-20160020.

39. Meletiadis J, Tsiodras S, Tsirigotis P. Interleukin-6 Blocking vs. JAK-STAT Inhibition for Prevention of Lung Injury in Patients with COVID-19. Infect Dis Ther. 2020;9:707-713. doi: 10.1007/s40121-020-00326-1.

40. Aziz M, Haghbin H, Abu Sitta E, Nawras Y, Fatima R, Sharma S, et al. Efficacy of tocilizumab in COVID-19: A systematic review and meta-analysis. J Med Virol. 2020;jmv.26509. doi: 10.1002/jmv.26509.

41. Hermine $\mathrm{O}$, Mariette $\mathrm{X}$, Tharaux $\mathrm{PL}$, Resche-Rigon $\mathrm{M}$, Porcher R, Ravaud P. Effect of Tocilizumab vs Usual Care in Adults Hospitalized with COVID-19 and Moderate or Severe Pneumonia: A Randomized Clinical Trial. JAMA Intern Med. 2020;181(1):32-40. doi: 10.1001/jamainternmed.2020.6820.

42. Roche. Roche's phase III EMPACTA study showed Actemra/ RoActemra reduced the likelihood of needing mechanical ventilation in hospitalised patients with COVID-19 associated pneumonia. 2020 [cited 2020 Dec 22]. Available from: https:// www.roche.com/investors/updates/inv-update-2020-09-18. $\mathrm{htm}$.

43. Qiu P, Cui X, Sun J, Welsh J, Natanson C, Eichacker PQ. Antitumor necrosis factor therapy is associated with improved survival in clinical sepsis trials: A meta-analysis. Crit Care Med. 2013;41:2419-2429. doi: 10.1097/CCM.0b013e3182982add.

44. Robinson PC, Richards D, Tanner HL, Feldmann M. Accumulating evidence suggests anti-TNF therapy needs to be given trial priority in COVID-19 treatment. Lancet Rheumatol. 
2020;2:e653-5. doi: 10.1016/S2665-9913(20)30309-x

45. Hajjar R, Chan G. Anti-tumor necrosis factor agents and COVID-19: A word of caution. J Clin Transl Res. 2020;6:9496. doi: 10.18053/Jctres/06.202003.004.

46. Lee JS, Shin EC. The type I interferon response in COVID-19: implications for treatment. Nat Rev Immunol. 2020;20:585586. doi: 10.1038/s41577-020-00429-3.

47. Zhou Q, Chen V, Shannon CP, Wei XS, Xiang X, Wang X, et al. Interferon- $a 2 b$ Treatment for COVID-19. Front Immunol. 2020;11:1061. doi: 10.3389/fimmu.2020.01061.

48. Satarker S, Tom AA, Shaji RA, Alosious A, Luvis M, Nampoothiri M. JAK-STAT pathway inhibition and their implications in COVID-19 therapy. Postgrad Med. 2021;133:489-507.doi: 10.1080/00325481.2020.1855921.

49. Zhang W, Zhao Y, Zhang F, Wang Q, Li T, Liu Z, et al. The use of anti-inflammatory drugs in the treatment of people with severe coronavirus disease 2019 (COVID-19): The experience of clinical immunologists from China. Clin Immunol. 2020;214:108393. doi: 10.1016/j.clim.2020.108393.

50. Olisova OY, Anpilogova EM, Svistunova DA. Apremilast as a potential treatment option for COVID-19: No symptoms of infection in a psoriatic patient. Dermatol Ther. 2020;33:e13668. doi: 10.1111/dth.13668.

51. El Mhammedi MA, Saqrane S, Lahrich S, Laghrib F, El Bouabi $\mathrm{Y}$, Farahi A, et al. Current trends in analytical methods for the determination of hydroxychloroquine and its application as treatment for COVID-19. ChemistrySelect. 2020;5:1460214612. doi: 10.1002/slct.202003361.

52. Of NI, Health. COVID-19 Treatment Guidelines Panel. Coronavirus Disease 2019 (COVID-19) Treatment Guidelines.

53. Long $\mathrm{H}, \mathrm{Xu}$ B, Luo $\mathrm{Y}$, Luo K. Artemisinin protects mice against burn sepsis through inhibiting NLRP3 inflammasome activation. Am J Emerg Med. 2016;34:772-7. doi: 10.1016/j. ajem.2015.12.075.

54. Wenisch C, Linnau KF, Looaresuwan S, Rumpold H. Plasma levels of the interleukin-6 cytokine family in persons with severe Plasmodium falciparum malaria. J Infect Dis. 1999;179:747-750. doi: 10.1086/314630.

55. Uzun T, Toptas O. Artesunate: Could be an alternative drug to chloroquine in COVID-19 treatment? Chinese Med (United Kingdom). 2020;15:54. doi: 10.1186/s13020-020-00336-8.

56. Gendrot $M$, Duflot I, Boxberger $M$, Delandre $O$, Jardot $P$, Le Bideau $M$, et al. Antimalarial artemisinin-based combination therapies (ACT) and COVID-19 in Africa: In vitro inhibition of SARS-CoV-2 replication by mefloquine-artesunate. Int J Infect Dis. 2020;99:437-440. doi: 10.1016/j.ijid.2020.08.032.

57. Kooistra EJ, Waalders NJB, Grondman I, Janssen NAF, de Nooijer AH, Netea MG, et al. Anakinra treatment in critically ill COVID-19 patients: a prospective cohort study. Crit Care. 2020;24:688. doi: 10.1186/s13054-020-03364-w.

58. Borie R, Savale L, Dossier A, Ghosn J, Taillé C, Visseaux B, et al. Glucocorticoids with low-dose anti-IL1 anakinra rescue in severe non-ICU COVID-19 infection: A cohort study. PLoS One. 2020;15:e0243961 doi: 10.1371/journal.pone.0243961.

59. Callaghan PJ, Rybakovsky E, Ferrick B, Thomas S, Mullin JM. Retinoic acid improves baseline barrier function and attenuates TNF-a-induced barrier leak in human bronchial epithelial cell culture model, 16HBE 14o. PLoS One. 2020;15:e0242536. doi: 10.1371/journal.pone.0242536.

60. Liang B, Chen J, Li T, Wu H, Yang W, Li Y, et al. Clinical remission of a critically ill COVID-19 patient treated by human umbilical cord mesenchymal stem cells: A case report. Medicine (Baltimore). 2020;99:e21429. doi: 10.1097/ MD.0000000000021429.

61. Shu L, Niu C, Li R, Huang T, Wang Y, Huang M, et al. Treatment of severe COVID-19 with human umbilical cord mesenchymal stem cells. Stem Cell Res Ther. 2020;11:361. doi: 10.1186/ s13287-020-01875-5.

62. Muccioli L, Pensato U, Bernabè G, Ferri L, Tappatà M, Volpi $\mathrm{L}$, et al. Intravenous immunoglobulin therapy in COVID-19related encephalopathy. J Neurol. 2020;1-5. doi: 10.1007/ s00415-020-10248-0.

63. Galeotti C, Kaveri S V., Bayry J. Intravenous immunoglobulin immunotherapy for coronavirus disease-19 (COVID-19). Clin Transl Immunol. 2020;9:e1198 doi: 10.1002/cti2.1198.

64. Narendrakumar L, Joseph I, Thomas S. Potential effectiveness and adverse implications of repurposing doxycycline in COVID-19 treatment. Expert Rev Anti Infect Ther. 2020;1-8 doi: 10.1080/14787210.2021.1865803.

65. Ghaed Amini F, Rafieian-Kopaei M, Nematbakhsh M, Azar Baradaran A, Nasri H. Ameliorative effects of metformin on renal histologic and biochemical alterations of gentamicininduced renal toxicity in Wistar rats. J Res Med Sci. 2013;17:621-5.

66. Cameron AR, Morrison VL, Levin D, Mohan M, Forteath C, Beall C, et al. Anti-Inflammatory Effects of Metformin Irrespective of Diabetes Status. Circ Res. 2016;119:652-665 doi: 10.1161/CIRCRESAHA.116.308445.

67. Hariyanto TI, Kurniawan A. Metformin use is associated with reduced mortality rate from coronavirus disease 2019 (COVID-19) infection. Obes Med. 2020;19:100290 doi: 10.1016/j.obmed.2020.100290.

68. Masser BM, Ferguson E, Thorpe R, Lawrence C, Davison TE, Hoad V, et al. Motivators of and barriers to becoming a COVID-19 convalescent plasma donor: A survey study. Transfus Med. 2021;31:176-185. doi: 10.1111/tme.12753.

69. Suh W, Urits I, Viswanath O, Kaye AD, Patel H, Hall W, et al. Three Cases of COVID-19 Pneumonia That Responded to Icosapent Ethyl Supportive Treatment. Am J Case Rep. 2020;21:e928422. doi: 10.12659/AJCR.928422.

70. Hong KS, Ahn JH, Jang JG, Lee JH, Kim HN, Kim D, et al. GSK-LSD1, an LSD1 inhibitor, quashes SARS-CoV-2-triggered cytokine release syndrome in-vitro. Signal Transduct Target Ther. 2020;5:267. doi: 10.1038/s41392-020-00391-5.

71. Francisqueti-Ferron FV, Garcia JL, Ferron AJT, NakandakareMaia ET, Gregolin CS, Silva JP das C, et al. Gamma-oryzanol as a potential modulator of oxidative stress and inflammation via PPAR-y in adipose tissue: a hypothetical therapeutic for cytokine storm in COVID-19? Mol Cell Endocrinol. 2021;520:111095. doi: 10.1016/j.mce.2020.111095.

72. DailyMed [Internet]. 2020 [cited 2020 Dec 29]. Available from: https://dailymed.nlm.nih.gov/dailymed/

73. Baricitinib in Combination with Remdesivir Reduces Time to Recovery in Hospitalized Patients with COVID-19 in NIAIDSponsored ACTT-2 Trial - Eli Lilly and Company [Internet]. [cited 2020 Dec 19]. Available from: https://investor.lilly.com/ news-releases/news-release-details/baricitinib-combinationremdesivir-reduces-time-recovery

74. Sanofi and Regeneron provide update on Kevzara ${ }^{\circledR}$ (sarilumab) Phase 3 U.S. trial in COVID-19 patients - Sanofi [Internet]. 2020 [cited 2020 Dec 28]. Available from: https://www.sanofi.com/ en/media-room/press-releases/2020/2020-07-02-22-30-00

75. Update on CALAVI Phase II trials for Calquence in patients hospitalised with respiratory symptoms of COVID-19 [Internet]. 2020 [cited 2020 Dec 20]. Available from: I Stem Cells for Severe COVID-19 Patients with Lung Damage: A Randomised, Double-Blind, Placebo-Controlled Phase 2 Trial. SSRN Electron J [Internet]. 2020 Oct 15 [cited 2021 Jan 2]; Available from: https://papers.ssrn.com/abstract=3680611

76. Simonovich VA, Burgos Pratx LD, Scibona P, Beruto M V., Vallone MG, Vázquez C, et al. A Randomized Trial of Convalescent Plasma in Covid-19 Severe Pneumonia. N Engl J 
Med. 2020;doi:10.1056/NEJMoa2031304.

77. Group RC. Dexamethasone in hospitalized patients with Covid-19-preliminary report. N Engl J Med. 2020;doi:10.1056/NEJMoa2021436.

78. Shi L, Huang H, Lu X, Yan X, Jiang X, Xu R, et al. Treatment with Human Umbilical Cord-Derived Mesenchymal Stem Cells for Severe COVID-19 Patients with Lung Damage: A Randomised, Double-Blind, Placebo-Controlled Phase 2 Trial. SSRN Electron J [Internet]. 2020 Oct 15 [cited 2021 Jan 2]; Available from: https://papers.ssrn.com/abstract=3680611.

79. Jeronimo CMP, Farias MEL, Val FFA, Sampaio VS, Alexandre MAA, Melo GC, et al. Methylprednisolone as Adjunctive Therapy for Patients Hospitalized With Coronavirus Disease 2019 (COVID-19; Metcovid): A Randomized, Double- blind, Phase IIb, Placebo-controlled Trial. Clin Infect Dis. 2021;72:e373-e381. doi:10.1093/cid/ciaa1177/5891816.

80. Hung IFN, Lung KC, Tso EYK, Liu R, Chung TWH, Chu MY et al. Triple combination of interferon beta-1b, lopinavirritonavir, and ribavirin in the treatment of patients admitted to hospital with COVID-19: an open-label, randomised, phase 2 trial. Lancet. 2020;3951695-1704 doi: 10.1016/S01406736(20)31042-4.

81. Novartis, Incyte: RUXCOVID Study Of Ruxolitinib In COVID-19 Patients Did Not Meet Primary Endpoint [Internet]. [cited 2021 Jan 2]. Available from: https://www.finanznachrichten. de/nachrichten-2020-12/51498168-novartis-incyte-ruxcovidstudy-of-ruxolitinib-in-covid-19-patients-did-not-meetprimary-endpoint-020.htm 